\title{
Experimental investigation on the changes in bed properties of a downdraft biomass gasifier
}

\author{
L. Kumararaja ${ }^{1 *}$, P. Gopinath Reddy ${ }^{1}$, M. Venkata Ramanan ${ }^{2}$, R. Sethumadhavan ${ }^{2}$ \\ ${ }^{1}$ Department of Mechanical Engineering, Pondicherry Engineering College, Puducherry, INDIA \\ ${ }^{2}$ Institute for Energy Studies, Anna University, Chennai, INDIA \\ *Corresponding Author: e-mail: lakuraja@gmail.com, Tel +91-9486008622, Fax.+91-413-2655101
}

\begin{abstract}
Biomass gasifiers of fixed bed, downdraft type are generally used for driving internal combustion engines. As part of research work, a versatile, throat type, biomass gasifier was developed. The gasifier had facilities for bed temperature measurements, pressure measurements, physical observation, sampling of bed particles, bed agitation, etc. The generated producer gas was cleaned and cooled in downstream components namely, cyclone separator, dust filter and gas cooler such that water had no direct contact with producer gas. The dry cleaned producer gas was flared directly at the exit pipe. Bed temperatures and bed char properties viz., weight, volume, density and volatile matter content along the gasifier axis, wood feeding rate, gasification air and producer gas flow rates, etc. were observed and analyzed during the gasification of wood pieces. Temperature stratification was found to depend on biomass bed height, phase of operation, location of reaction zones and reactor pressure. Specific gasification rate for wood pieces was found to be $75 \mathrm{~kg} \mathrm{~h}^{-1} \mathrm{~m}^{-2}$ which was lesser than that for loose bioresidues. Mass balance was also done for the gasification system. The producer gas to wood ratio was determined to be 2.39 at an optimum equivalence ratio of 0.3 . The volume of wood piece or char decreased by as high as $86 \%$ even before it enters the reduction zone of the gasifier.
\end{abstract}

Keywords: Biomass; Downdraft gasifier; Packed bed; Temperature profile; Bed properties

\section{Introduction}

Biomass is one of the renewable energy resources which can help us to tackle any adverse situation arising out of depletion of fossil fuels. Realizing the potential of biomass, MNRE, India (Annual Report, 2007-08) embarked on a program for strategic development of biomass. The emphasis is to develop more efficient biomass gasification system comprising of gasifier, gas cleaning and cooling devices. Gasification system coupled to engine-genset for electric power generation is an attractive option for the utilization of biomass. Engine-gensets of capacity as high as $1.2 \mathrm{MWe}$ are developed to run on a higher percentage of producer gas (PG) in diesel + PG mode.

Gasifiers which convert any biomass to PG are being researched and perfected worldwide by many researchers. As part of research and development, many researchers have reported their results on temperature profiles, product gas composition, reaction zone propagation rates etc., in the gasifier bed for different types of biomass. Bhattacharya et al. (1986) experimentally analyzed coal char gasification in a bench-scale, throat-less, cylindrical reactor and obtained temperature profile along the gasifier axis. Khater et al. (1992) studied the gasification of rice hulls in a throat-less, downdraft gasifier and measured the bed temperatures at five locations along the gasifier axis. Blasi (2000) developed a mathematical model to predict the axial temperature distribution, variations in solid particle velocity and particle volume along the gasifier. Dasappa et al. (2001) carried out an experimental study and analysis of gasification of char particles in packed beds to determine the propagation front movement, gas and solid temperatures in the bed. Dogru et al. (2002) developed a $5 \mathrm{~kW}$ capacity downdraft gasifier and experimented in it the gasification of hazelnut shells. The average zone temperatures, PG composition, and by-product yields were determined experimentally.

But research upon the changes in bed material properties while undergoing gasification are only limited. The primary objective of the work was to develop a gasification system and to analyze the temperature profiles, biomass bed properties, etc. during 
gasification. The gasification system can be used later to drive an engine + genset. Few types of biomass like wood pieces, wood shavings, groundnut shells, coir pith and charcoal were gasified in the gasifier. The results obtained during the gasification of wood pieces are discussed in this paper.

\section{Experimental set-up and procedure}

2.1. Description of system: The gasifier is a packed bed reactor of variable configuration type. It has been designed such that it can be used as (i) downdraft or updraft gasifier and (ii) throat type or throat-less, open core type gasifier. It can be operated by forcing air from an air blower to it or by inducing air through the gasifier by means of a suction blower or an internal combustion engine. Depending upon the experimental condition, the gasifier can be suitably configured and used for any type of biomass. In the present experiment, it was operated as a throat type, forced mode, downdraft gasifier.

The experimental system consists of centrifugal blower, downdraft gasifier, flare pipe, cyclone separator, dust filter and gas cooler. The layout diagram of the gasification system is shown in Figure 1. The motorized centrifugal blower supplies air to the gasifier. The air supply from the blower is regulated by a valve. The air flow adjustment is important for uninterrupted and successful operation of gasifier. The air flow rate is measured by an orifice meter made up of SS 316 material. Air enters the gasifier through an air inlet pipe at the top. The biomass is fed through a feeding port, which is also provided at the top of gasifier. The biomass feeding port is kept closed during operation of gasifier and it is opened only at the time of feeding biomass. The gasifier is a cylindrical shell which is lined inside with medium density castable refractory to withstand high temperature. Eight numbers of chromel-alumel (K-type) thermocouples are provided along the height of gasifier at regular intervals. They measure bed temperatures closer to the wall inside the gasifier. In order to observe the reaction front and to take out solid samples from the bed, four removable sight glasses are also provided along the gasifier axis at four levels. The packed biomass bed in the gasifier can be periodically agitated by means of a specially designed leveling rod. To support the biomass bed, a perforated stainless steel grate is provided below the throat portion of gasifier. The residual char and ash falling from the grate are collected in a closed ash chamber. At the end of experiment, they are cleared out by means of a lateral ash port.

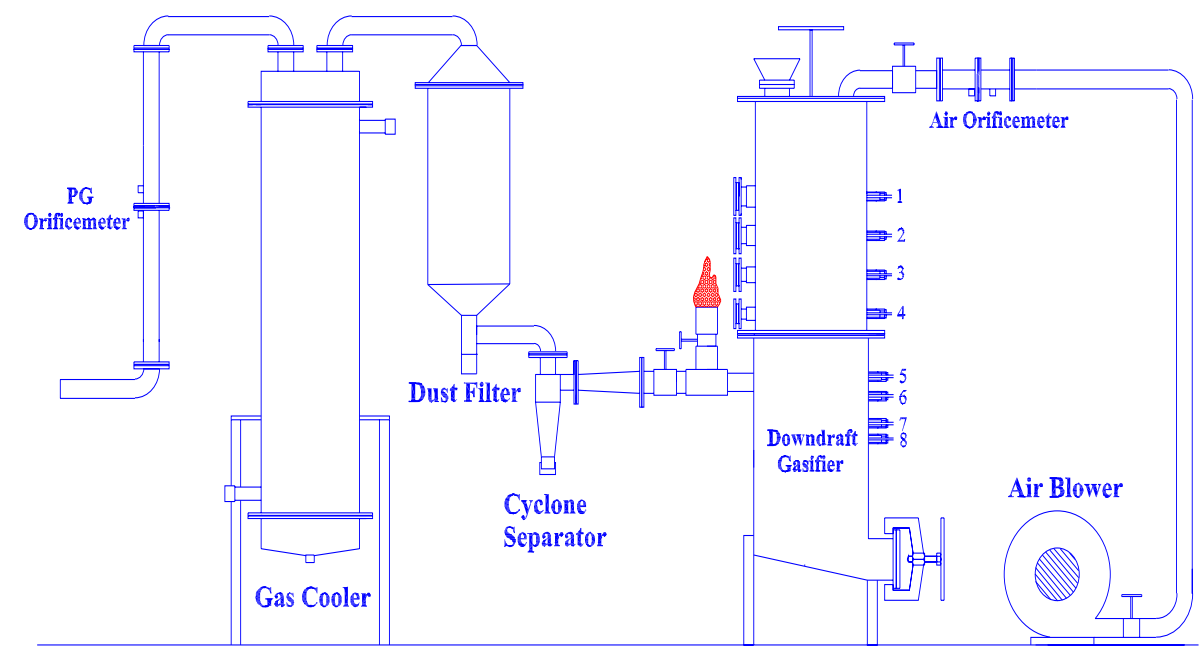

Figure 1. Layout of biomass gasification system

The PG exiting the gasifier is passed to a cyclone separator to remove coarser dust particles. Then it is sent to a dust filter for hot gas cleaning at about $300^{\circ} \mathrm{C}$. In dust filter, the gas passes through four filter elements fabricated out of SS mesh of size No. 100. The filter elements can retain dust greater than 152 micron size and they have free open area of $36 \%$. Since the gasifier capacity is less and water scrubbing is unattractive due to the economics and environmental pollution of effluent water (Rapagna et al, 2002), dry cleaning of PG is preferred.

The dry cleaned, hot PG is then passed through a gas cooler which is a shell and tube heat exchanger. Cooling water is supplied in the shell side while PG flows through the tubes. In gas cooler, PG does not directly contact cooling water. The condensed water and tar collected at the bottom end cover of the gas cooler is drained out periodically. The detailed specifications of the gasification system are given in Table 1. The PG flow rate is measured by an orifice meter made up of SS 316 material.

There is also a provision to flare the PG directly after the gasifier without passing it through any downstream equipment. A torch is used to ignite the PG emanating from the flaring pipe. 
Table 1. Specifications of gasification system

\begin{tabular}{|c|c|}
\hline Blower: & \\
\hline Centrifugal type; cast impeller & \\
\hline Air flow rate: $60 \mathrm{cfm}$ & Head: $12 \mathrm{~cm} \mathrm{WC} \mathrm{( \operatorname {max } )}$ \\
\hline Gasifier: & \\
\hline Downdraft; throat type; air entry at top of th & \\
\hline Diameter: $290 \mathrm{~mm}$ & Height: $1400 \mathrm{~mm}$ \\
\hline Grate: Stainless Steel, perforated & Throat diameter: $100 \mathrm{~mm}$ \\
\hline Insulation: $\mathrm{Al}_{2} \mathrm{O}_{3}$ based castable refractory & Feeding port: Circular, $\varnothing=100 \mathrm{~mm}$ \\
\hline Cyclone Separator: & \\
\hline High efficiency; tangential inlet & \\
\hline Entry: Rectangular, $18 \mathrm{~mm}$ x $35 \mathrm{~mm}$ & Exit: Circular, $\varnothing=42 \mathrm{~mm}$ \\
\hline Dust Filter: & \\
\hline 4 filter elements; dust collected on outer su & elements \\
\hline Filter elements: Cylindrical, $\varnothing=40 \mathrm{~mm}$ & Body: Cylindrical, $\varnothing=250 \mathrm{~mm}$ \\
\hline Gas Cooler: & \\
\hline 2 tube pass, 1 shell pass, shell and tube type & anger; vertical \\
\hline Tubes: 6 tubes per pass, $\varnothing=33 \mathrm{~mm}$ & Shell: $\varnothing=300 \mathrm{~mm}$, Length $=1050 \mathrm{~mm}$ \\
\hline
\end{tabular}

2.2. Operating procedure: Initially, $1 \mathrm{~kg}$ charcoal was charged on the grate up to a height just above the throat of the gasifier. The charcoal bed was ignited and wood pieces in batches each of $1 \mathrm{~kg}$ mass were charged over the red hot charcoal bed through the feeding port. The addition of wood pieces in batches was done at regular time intervals; because of which biomass bed height increased as shown in Figure 2. The PG generated by the gasifier was test flared directly for about 10 minutes without cleaning and cooling. Afterwards, test flaring was stopped and the entire PG was allowed to flow through the downstream components for cleaning and cooling; because, gas cleaning and cooling will be indispensable for future engine-genset application. During the test duration, the PG continued to flow through the cleaning and cooling train and its flow rate was measured using orifice meter. The PG was flared at the pipe exit. The photographic view of the test set-up is shown in Figure 3.

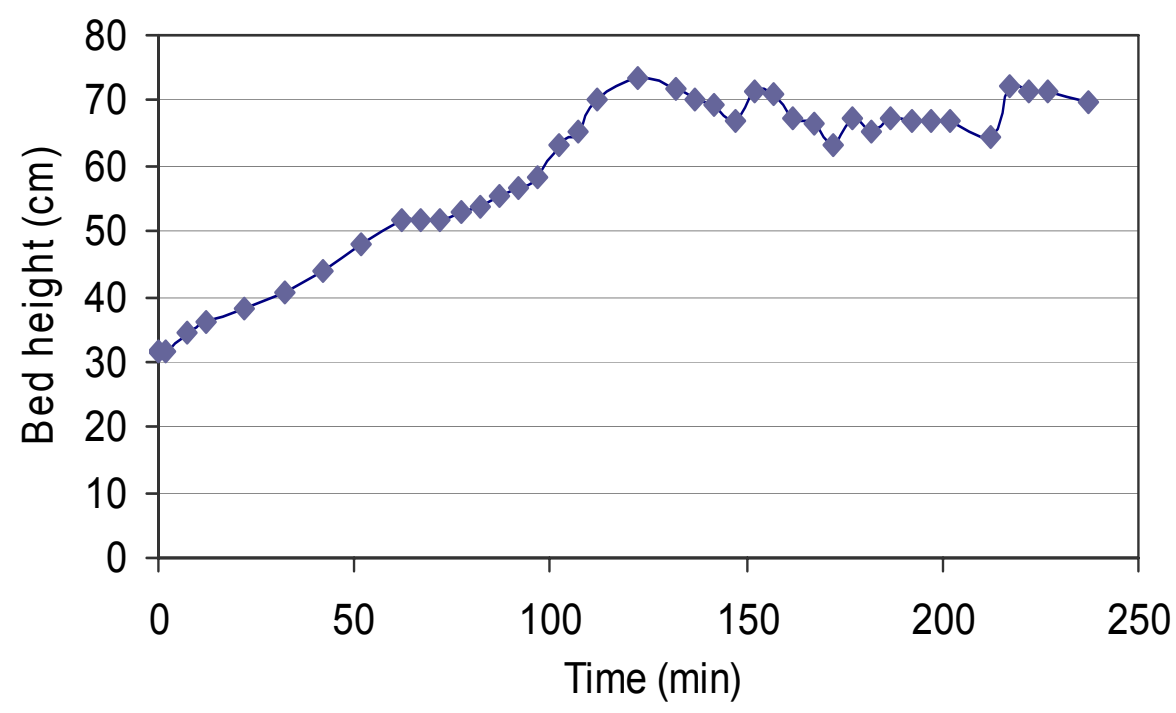

Figure 2. Plot of biomass bed height during the test period 
The following parameters were measured at regular time intervals for the entire test period of 4 hours.

(i) Air flow rate to gasifier,

(ii) Wood feed rate,

(iii) Biomass bed height,

(iv) Bed temperatures at eight locations along the gasifier axis,

(v) Pressures at four locations along the gasifier axis,

(vi) PG temperature at gasifier outlet,

(vii) PG temperature at gas cooler outlet,

(viii) PG flow rate, and

(ix) Condensate collection rate

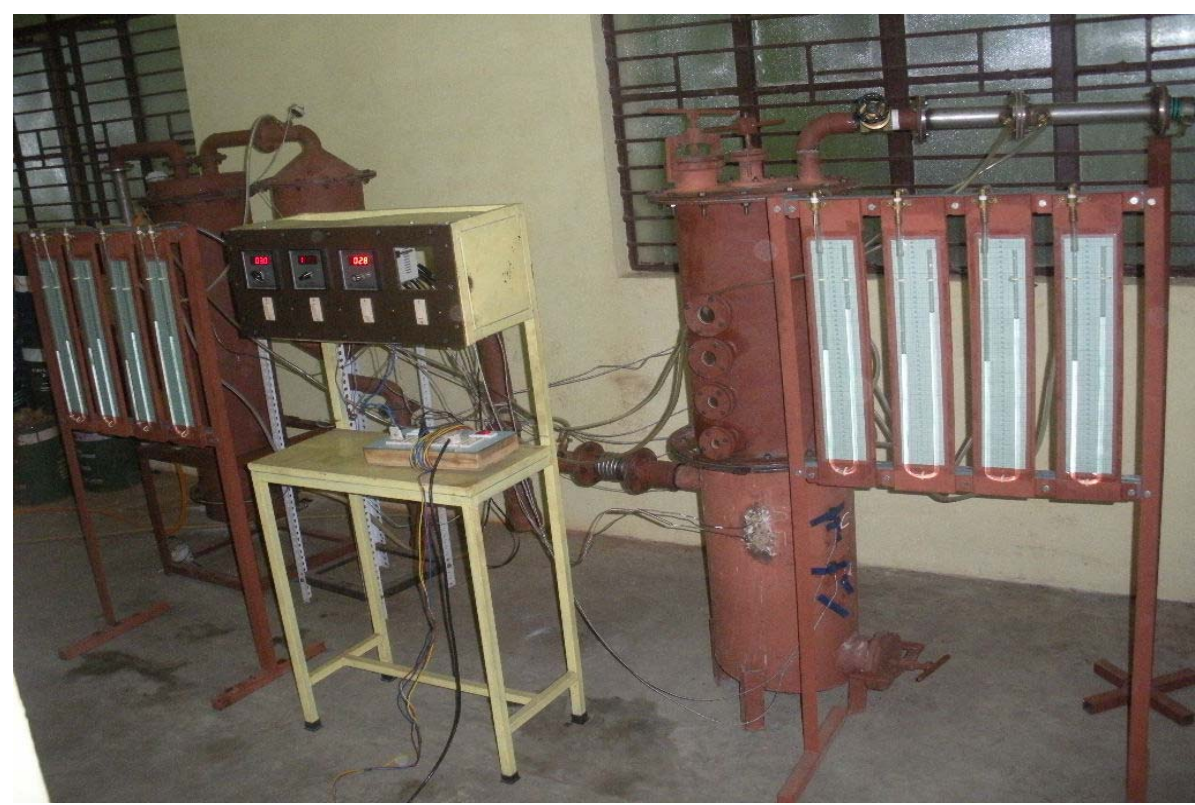

Figure 3. Photographic view of experimental set-up

Biomass bed height was maintained constant for about 2 hours as shown in Figure 2 by regulated charging of biomass; this was done in order to measure all the above parameters during steady phase. Bed particles were sampled at five levels along the gasifier axis to determine the bed properties. The gasifier was then stopped and cooled. The residual char and ash present in the gasifier were weighed. The dust particles collected at the bottom of cyclone separator and dust filter were also weighed. The major operating parameters of the gasification system are given in Table 2 .

Table 2. Operating parameters of gasification system

\begin{tabular}{ll}
\hline \hline \multicolumn{1}{c}{ Operating parameter } & \multicolumn{1}{c}{ Value } \\
\hline \hline Duration of experiment & $4 \mathrm{~h}$ \\
\hline Gasification air flow rate & $8.95 \mathrm{~kg} \mathrm{~h}^{-1}$ \\
\hline Pressure of air supply & $20 \mathrm{~mm} \mathrm{WC}$ \\
\hline Wood piece dimensions & $45 \mathrm{~mm} \mathrm{x} 45 \mathrm{~mm} \mathrm{x} 35 \mathrm{~mm}$ \\
\hline Name of wood & Silver oak \\
\hline Wood feed rate & $4.78 \mathrm{~kg} \mathrm{~h}^{-1}$ \\
\hline PG flow rate & $11.95 \mathrm{~kg} \mathrm{~h}^{-1}$ \\
\hline Condensate collection rate & $1.68 \mathrm{~kg} \mathrm{~h}^{-1}$ \\
\hline Cooling water flow rate in gas cooler & $1.5 \mathrm{~kg} \mathrm{~min}^{-1}$ \\
\hline \hline
\end{tabular}




\section{Results and Discussion}

3.1. Bed height: The biomass bed height inside the gasifier can be varied by changing the rate of biomass feeding into the gasifier. When the rate of biomass feeding is greater than the rate of gasification, the bed height will increase. In the experiment, bed height was increased from an initial value to about $70 \mathrm{~cm}$ in 2 hours; which was regarded as transient phase. Afterwards, the bed height was maintained constant at about $70 \mathrm{~cm}$ for 2 hours; which was regarded as steady phase operation. The variation in biomass bed height with time during the experiment has been already shown in Figure 2. The biomass inventory of the gasifier i.e., bed height governed the bed temperature distribution. The temperature distribution in the bed differed between transient and steady phases.

3.2. Bed temperatures: At any point of time, the temperature distribution in the gasifier is a good indication of the nature of chemical reactions occurring in the gasifier. Eight chromel-alumel ( $\mathrm{K}$ - type) thermocouples protruding about $10 \mathrm{~mm}$ inside the gasifier measured the bed temperatures. Figure 4 shows the variation of bed temperatures with time period of the experiment. It is evident from Figure 4 that there existed temperature stratification along the gasifier axis at any instant. The zone where peak temperature occurs is generally construed to be the oxidation zone. In the experiment, a maximum temperature of $750^{\circ} \mathrm{C}$ was recorded in the convergent portion at T5. Boateng et al. (2007) reported a maximum temperature of $650^{\circ} \mathrm{C}$ in a farm-scale reactor for Kentucky bluegrass straw. Zainal et al. (2002) showed that the fluctuations in the temperature profile of oxidation zone were wide due to improper and intermittent contact between bed particles and thermocouple tip.

3.3. Biomass bed height and oxidation zone: A comparison between Figs. 2 and 4 shows that when biomass bed height was increased in the gasifier, location of peak temperature i.e., the oxidation zone progressed upstream even though air flow rate was kept constant at $8.95 \mathrm{~kg} \mathrm{~h}^{-1}$. The location of peak temperature shifted from T5 through T4, T3 to T2. So it may be concluded that the oxidation zone can be made to move through the bed by varying the biomass bed height even if air flow rate is kept constant. On the other hand, if biomass bed height is maintained constant, oxidation zone can be made dynamic just by varying the air

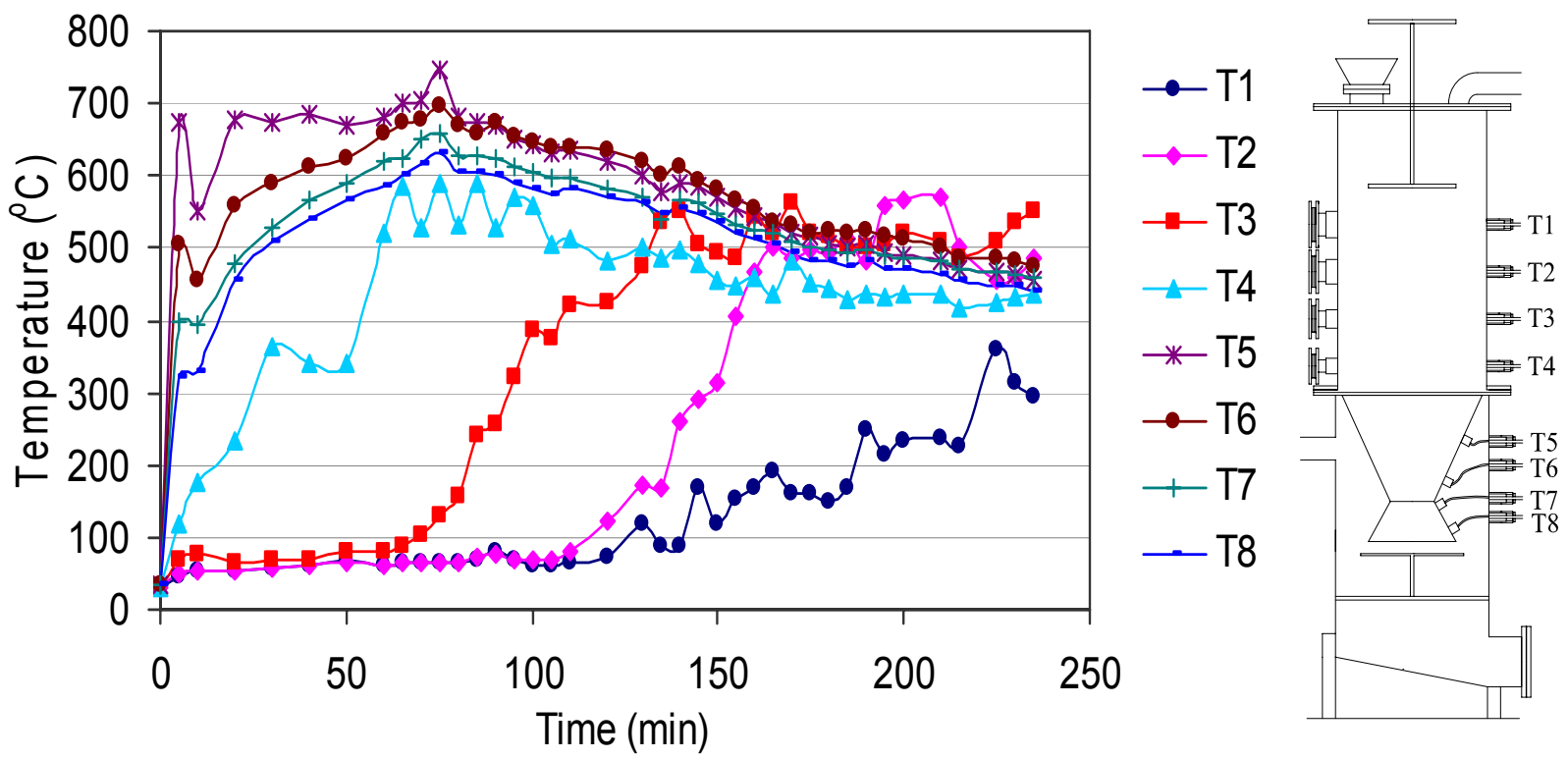

Figure 4. History of bed temperatures in gasifier

flow rate. So the oxidation zone location can be governed by either regulating the air flow rate or the biomass bed height or both.

3.4. Phase of operation and temperature stratification: The temperature differences were calculated as follows:

$\Delta \mathrm{T}_{\mathrm{A}}=\mathrm{T} 2-\mathrm{T} 1 ; \quad \Delta \mathrm{T}_{\mathrm{B}}=\mathrm{T} 3-\mathrm{T} 2 ; \quad \Delta \mathrm{T}_{\mathrm{C}}=\mathrm{T} 4-\mathrm{T} 3 ; \quad \Delta \mathrm{T}_{\mathrm{D}}=\mathrm{T} 5-\mathrm{T} 4 ;$

$\Delta \mathrm{T}_{\mathrm{E}}=\mathrm{T} 6-\mathrm{T} 5 ; \quad \Delta \mathrm{T}_{\mathrm{F}}=\mathrm{T} 7-\mathrm{T} 6 ; \quad \Delta \mathrm{T}_{\mathrm{G}}=\mathrm{T} 8-\mathrm{T} 7$

From temperature measurements, temperature differences were determined and they are shown in Figure 5. In the beginning of gasifier operation i.e. transient phase, significant temperature differences also called as temperature stratification existed along the gasifier axis. But during steady phase, even though temperature stratification prevailed along the height of gasifier, the magnitude of differences diminished. The average temperature of bed contents was also high during steady phase. The temperature differences were the result of distinct physical changes and chemical reactions that had been taking place along the height of gasifier. $\Delta \mathrm{T}_{\mathrm{C}}$ was found to be the highest. 
3.5. Reaction zones and temperature stratification: During any phase, it may be also observed from Figure 5 that larger temperature stratification existed above the oxidation zone in the drying and devolatilization zones due to opposite directions of heat transfer and air + biomass flow and also due to chemical reactions. But below the oxidation zone, temperature stratification was lesser due to better heat transfer and also meager reduction reaction rates below $600^{\circ} \mathrm{C}$ down the gasifier axis. Radulovic et al. (1995) obtained similar results both in their experiments and in the model for fixed bed coal gasification.
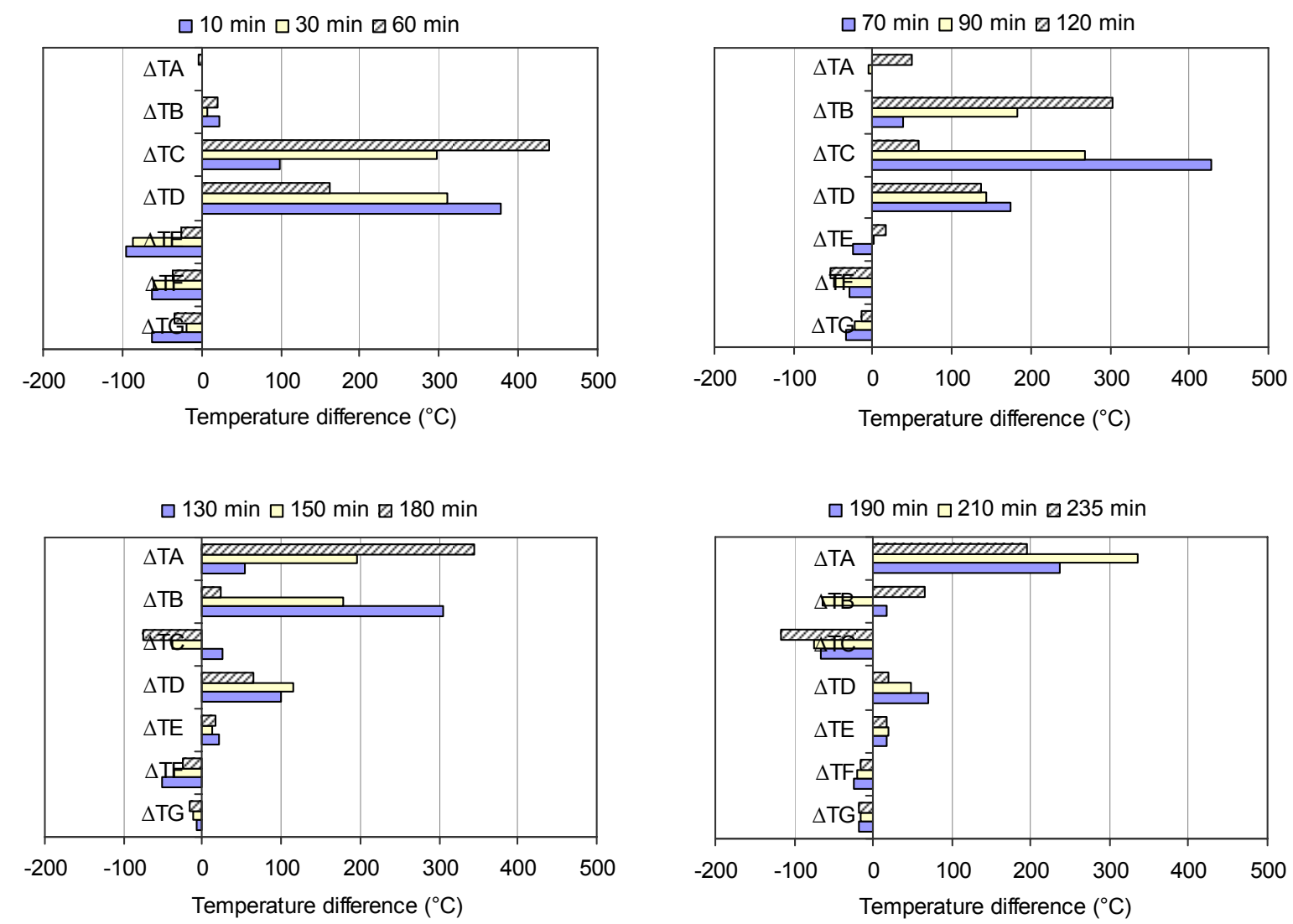

Figure 5. Temperature differences between adjacent thermocouples of gasifier

3.6. Reactor pressure and temperature stratification: To overcome the gasification system pressure drop, an auxiliary blower is generally provided in the process line. It can be provided on either upstream or downstream side of the gasifier. If it is provided on upstream side like as shown in Figure 1, the gasifier will have positive pressure and it is said to be operating in blowing mode. On the other hand, if a blower or engine is connected on downstream side, the gasifier will have negative pressure and it is said to be operating in suction mode.

The temperature stratification in devolatilization zone was significant when the gasifier was run in suction mode. Because, the heat transfer from oxidation zone to devolatilization and drying zones took place mainly by conduction through biomass bed. The conduction heat transfer is generally the slowest and hence there existed significant temperature stratification. But in blowing mode, temperature stratification was comparatively lesser in devolatilization and drying zones because of the more dynamic reaction zones. Besides, air supplied from the blower had convected briefly above the biomass bed before passing through it. So heat transfer occurred both by conduction and convection, thereby minimizing temperature stratification. The reaction front could progress upstream or recede downstream along the bed even for minor changes in the operating parameters.

3.7. Throat and oxidation zone: Generally, a throat type gasifier is designed such that oxidation reactions occur in the convergent portion of the gasifier. In the present experiment too, the temperatures T5 \& T6 remained higher (refer Figure 4) for most of the time, indicating that oxidation zone was located in the convergent portion of the gasifier. Coovattanachai (1989) reported that due to high temperature at throat, tar could be thermally cracked. This is also one of the important conditions for the determination of optimum biomass inventory i.e. biomass bed height in the gasifier.

3.8. Properties of bed particles: The physical and chemical properties of biomass particles continuously change due to various reactions in the biomass bed. Besides temperature, the determination of properties of the bed contents at different heights along the gasifier helps to know the type of chemical reactions and their locations. In the present experiment, bed particles were sampled 
from gasifier at five places along its axis. For each particle, the weight, the volume and the volatile matter content were measured and then its density was calculated. Volatile matter content was determined as per ASTM standards D 1762-84.

The decrease in the weight of a bed particle down the gasifier axis is shown in Figure 6. The decrease in the volume of a bed particle down the gasifier axis is shown in Figure 7. Comparison of Figures 6 and 7 shows that weight reduction rate is more than volume reduction rate. When wood pieces were heated, evolution of volatiles was faster than the combustion of surface solid char particles. The devolatilization rate of biomass reaches a maximum at $400^{\circ} \mathrm{C}$ (Biagini et al, 2002). Giltrap et al. (2003) also

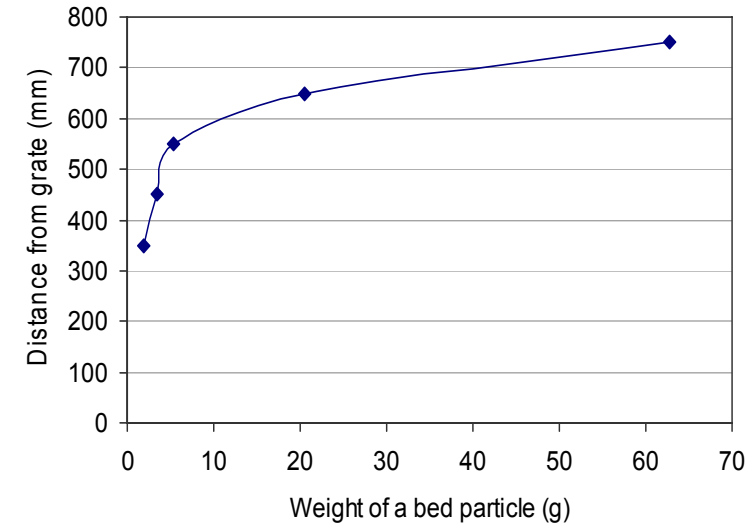

Figure 6. Decrease in weight of a bed particle down the gasifier axis

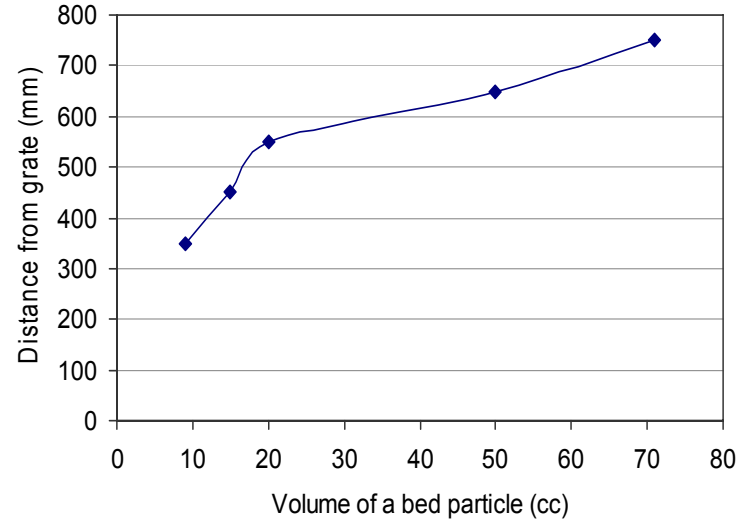

Figure 7. Decrease in volume of a bed particle down the gasifier axis

reported that flaming pyrolysis would take a lead over char particle combustion.

The decrease in the density of bed particles down the gasifier axis is shown in Figure 8. The decrease in volatile matter content of bed particles down the gasifier axis is shown in Figure 9. It shows that the volatile matter content becomes just $1 \%$ at the

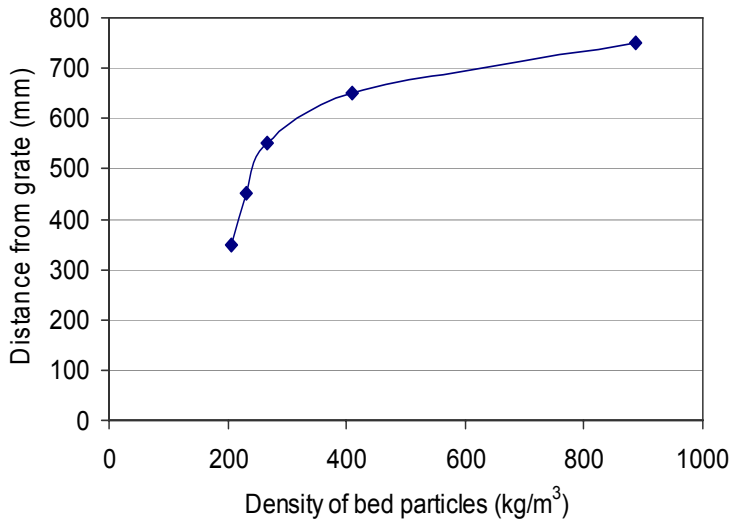

Figure 8. Decrease in density of bed particles down the gasifier axis

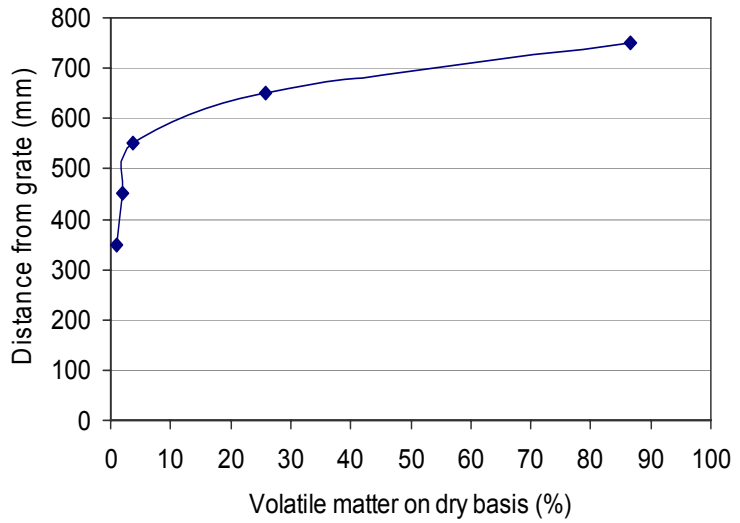

Figure 9. Decrease in volatile matter content down the gasifier axis

bottom-most sample port. Because of such a very low value, char can undergo only glowing combustion below the level of bottom-most sample port. The top most point in each graph shows the value for raw wood piece.

The determination of volatile matter content of bed particles can help to find out the exact length of devolatilization zone in the gasifier. From the knowledge of length of devolatilization zone, the oxidation zone can be located inside the gasifier. It should be present ideally in the convergent portion of the gasifier. Devolatilization zone length may be expected to be shorter for bioresidues like rice husk, groundnut shell, etc., than that for wood pieces. This is due to faster release of volatiles from loose bioresidues when compared to wood pieces.

3.9. Specific gasification rate: It is the rate at which biomass is gasified per unit cross sectional area of the gasifier. For gasification of rice husk, it was reported as $960 \mathrm{~kg} \mathrm{~h}^{-1} \mathrm{~m}^{-2}$ in a circulating fluidized bed gasifier and $127 \mathrm{~kg} \mathrm{~h}^{-1} \mathrm{~m}^{-2}$ in a downdraft fixed bed gasifier (Yin et al, 2002). Furthermore, the type of biomass, gasifying agent, gasifier design and operating conditions control the specific gasification rate (Tiangco et al, 1996). In the present experiment, it was determined as $75 \mathrm{~kg} \mathrm{~h}^{-1} \mathrm{~m}^{-2}$. The low value of specific gasification rate is due to the use of wood pieces as gasifier feedstock in the experiment, instead of loose bioresidues. 
3.10. Mass Balance in gasification system: Considering the entire gasification system as a thermodynamic system, overall mass balance was determined between the inlet and exit mass flow streams for the total time period of experiment of 4 hours. The overall mass balance is shown in Table 3 .

Table 3. Overall mass balance of gasification system

\begin{tabular}{clc|clc}
\hline \hline $\begin{array}{c}\text { Sl. } \\
\text { No. }\end{array}$ & Inlet mass flow stream & $\begin{array}{c}\text { Quantity } \\
(\mathrm{kg})\end{array}$ & $\begin{array}{c}\text { Sl. } \\
\text { No. }\end{array}$ & Exit mass flow stream & $\begin{array}{c}\text { Quantity } \\
(\mathrm{kg})\end{array}$ \\
\hline \hline 1 & Gasification air & 35.80 & 1 & Producer Gas & 47.80 \\
\hline 2 & Wood pieces & 24.00 & 2 & Condensate + tar & 6.72 \\
\hline 3 & Initial amount of charcoal & 1.00 & 3 & Residual char in gasifier & 5.07 \\
\hline- & -- & --- & 4 & Particulates & 0.32 \\
\hline- & --- & --- & 5 & Unaccounted & 0.89 \\
\hline & Total & 60.80 & & Total & 60.80 \\
\hline \hline
\end{tabular}

\section{Conclusions}

A gasification system consisting of gasifier, blower, cyclone separator, dust filter, and gas cooler was developed for biomass. Experiments were conducted to study the biomass bed temperature profiles in the gasifier, bed property changes during gasification and overall performance of the gasification system. The following important conclusions are derived from the observations, results and analysis. When the biomass bed height was increased in the gasifier by means of excessive feeding, the reaction front propagated upwards in the bed. This happened despite maintaining air flow rate constant. So, the reaction front can be made dynamic by either regulating the air flow rate or the biomass bed height or both. Temperature difference per unit length of bed i.e., temperature stratification was larger during transient phase but comparatively lesser during steady phase operation. It was also not uniform, being higher in devoltilization zone than in reduction zone. Devolatilization reactions were faster than reduction reactions. In the devolatilization zone, temperature stratification during suction mode operation was more than that during blowing mode operation. The physical and chemical properties viz., weight, volume, density and volatile matter content of bed particles decreased continuously down the gasifier axis. The rate of decrease in the weight of bed particles was faster than that in the volume of bed particles. The volume of wood piece or char decreased by as high as $86 \%$ even before it enters the reduction zone of the gasifier. The determination of volatile matter content of bed particles in the gasifier helped to find out the length of devolatilization zone. Devolatilization zone length may be expected to be shorter for loose bioresidues like rice husk, groundnut shell, etc., than that for wood pieces. Stratification of bed temperature and gradation of bed properties down the gasifier axis were essentially the characteristic features of fixed bed downdraft biomass gasifier. The specific gasification rate for solid wood pieces was found to be $75 \mathrm{~kg} \mathrm{~h}^{-1} \mathrm{~m}^{-2}$ which was lesser than that for loose bioresidues in a fixed bed downdraft gasifier. Finally, the calculation of mass balance for the gasifier helped to assess its performance. From mass balance calculations, the producer gas to wood ratio was determined to be 2.39 corresponding to an equivalence ratio of 0.3 .

The biomass gasification system can be also connected to an engine with electrical generator set and the performance of total system can be studied. Parameters like pressure distribution, temperature distribution, bed properties, gas quality, efficiency etc., can be specifically analysed for gasifier in the total gasifier with engine and generator system. Different bioresidues can be used in the gasifier and in each case the total system performance can be determined. A comparison and ranking of bioresidues based on their suitability of gasification will be possible based on such studies.

\section{Acknowledgement}

The first two authors acknowledge the extension of facilities for this research by Pondicherry Engineering College, Puducherry.

\section{References}

Annual Report, 2007-08, Ministry of New and Renewable Energy (MNRE), Government of India.

Bhattacharya A, Salam L, Duduković MP, Joseph B.,1986. Experimental and modeling studies in fixed-bed char gasification.

Industrial \& Engineering Chemistry Process Design and Development, Vol. 25, pp. 988-996.

Biagini E, Lippi F, Petarca L, Tognotti L., 2002. Devolatilization rate of biomasses and coal-biomass blends: an experimental 
investigation. Fuel, Vol. 81, pp. 1041-1050.

Blasi C.D., 2000. Dynamic behaviour of stratified downdraft gasifiers. Chemical Engineering Science, Vol. 55, pp. 2931-2944.

Boateng AA, Banowetz G.M., Steiner J.J., Barton T.F., Taylor D.G., Hicks K.B., El-Nashaar H., Sethi V.K. 2007. Gasification of

Kentucky bluegrass (Poa pratensis I) straw in a farm-scale reactor. Biomass \& Bioenergy, Vol. 31, pp.153-161.

Coovattanachai N., 1989. Biomass gasification research and field developments by the Prince of Songkla University, Thailand.

Biomass, Vol. 18, pp. 241-271.

Dasappa S., Paul P.J.., 2001. Gasification of char particles in packed beds: analysis and results. International Journal of Energy

Research, Vol. 25, pp. 1053-1072.

Dogru M., Howarth C.R., Akay G., Keskinler B., Malik A.A., 2002. Gasification of hazelnut shells in a downdraft gasifier. Energy, Vol. 27, pp. 415-427.

Giltrap D.L., McKibbin R., Barnes G.R.G., 2003. A steady state model of gas-char reactions in a downdraft biomass gasifier. Solar Energy, Vol. 74, pp. 85-91.

Khater E.M.H., El-Ibiary N.N., Khattab I.A., Hamad M.A., 1992. Gasification of rice hulls. Biomass \& Bioenergy, Vol. 3, pp. 329333.

Radulovic P.T., Ghani M.U., Smoot L.D., 1995. An improved model for fixed bed coal combustion and gasification. Fuel, Vol. 74, pp. 582-594.

Rapagna S., Provendier H., Petit C., Kiennemann A., Foscolo P.U., 2002. Development of catalysis suitable for hydrogen or syngas production from biomass gasification. Biomass \& Bioenergy, Vol. 22, pp. 377-388.

Tiangco V.M., Jenkins B.M., Goss J.R., 1996. Optimum specific gasification rate for static bed rice hull gasifiers. Biomass \& Bioenergy, Vol. 11, pp. 51-62.

Yin X.L., Wu C.Z., Zheng S.P., Chen Y., 2002. Design and operation of a CFB gasification and power generation system for rice husk. Biomass \& Bioenergy, Vol. 23, pp. 181-187.

Zainal Z.A., Rifau A., Quadir G.A., Seetharamu K.N., 2002. Experimental investigation of a downdraft biomass gasifier. Biomass \& Bioenergy, Vol. 23, pp. 283-289.

\section{Biographical notes}

L. Kumararaja received B. E. (Mechanical) from Mysore University, Mysore and M. Tech (Energy Conservation and Management) from Bharathidasan University, Tiruchirappalli. He is working as Senior Lecturer in the Dept. of Mechanical Engineering of Pondicherry Engineering College, Puducherry. He is doing Ph. D. at Anna University, Chennai. He is a member of Institution of Engineers, India; ISTE; Solar Energy Society of India; The Combustion Institute and Energy and Fuel Users Association of India.

P. Gopinath Reddy received B. Tech (Mechanical) from Pondicherry Engineering College, Puducherry, and currently doing M.S. at United States of America.

M. Venkata Ramanan received B. E. (Mechanical) from Madras University, M. Tech (Energy Conservation and Management) from Bharathidasan University, Tiruchirappalli, and Ph. D. from Anna University, Chennai. He is working as Senior Lecturer in Institute for Energy Studies, Anna University, Chennai.

R. Sethumadhavan received B. E. (Chemical) from CIT, Coimbatore, and Ph. D from Indian Institute of Technology Bombay. He is working as Professor in Institute for Energy Studies, Anna University, Chennai.

Received June 2010

Accepted August 2010

Final acceptance in revised form August 2010 